\title{
Energy Efficient TABU Optimization Routing Protocol for WSN
}

\section{Protocolo de enrutamiento de optimización TABU de bajo consumo de energía para WSN}

\section{Protocolo de Roteamento de Otimização TABU com Eficiência Energética para RSSF}

\author{
Varsha Shani ${ }^{1}$ \\ Manju Bala² \\ Manoj Kumar ${ }^{3}$ \\ Neeraj Kumar ${ }^{4}$
}

Received: May $17^{\text {th }}, 2020$

Accepted: July $30^{\text {th }}, 2020$

Available: September $2^{\text {th }}, 2020$

How to cite this article:

Varsha, Manju Bala, Manoj Kumar, Neeraj Kumar, "Energy Efficient TABU Optimization Routing Protocol for WSN," Revista Ingeniería Solidaria, vol. 16, no. 3, 2020. doi: https://doi.org/10.16925/2357-6014.2020.03.07

Artículo de investigación. https://doi.org/10.16925/2357-6014.2020.03.07

1 IKG PTU Regional Centre, Jalandhar (Punjab), India

ORCID: https://orcid.org/0000-0001-7965-6552

E-mail: barkhabright@gmail.com; varsha.548@ctgroup.in

2 Khalsa College of Engineering \& Technology, Amritsar, (Punjab), India.

ORCID: https://orcid.org/0000-0002-2752-685X

E-mail: drmanju571@gmail.com

3 DAV institute of Engineering, Management \& Technology, Jalandhar (Punjab), India.

ORCID: https://orcid.org/0000-0001-9598-0280

E-mail: drmanojkumarindia@gmail.com

4 DIT, BBAU (A Central University), Lucknow, India.

ORCID: https://orcid.org/0000-0002-2126-2830

E-mail: req.mrt@gmail.com 


\section{Abstract}

Introduction: This article is the result of the research "Energy efficient routing protocols in wireless sensor network: Examine the impact of M-SEEC routing protocols on the lifetime of WSN with an energy efficient TABU optimization routing protocol"developed in the IKG, Punjab Technical University, India in 2019.

Problem: The task of finding and maintaining routes in WSNs is non-trivialsince energy restrictions and sudden changes in node status cause frequent and unpredictable changes.

Objective: The objective of this paper is to propose an energy efficient heterogeneous protocolwith the help of a hybrid meta-heuristic technique.

Methodology: In the hybrid meta-heuristic technique, the shortest route has been selected and the data forwarded to the sink in a minimal time span,savingenergy and making the network more stable. To evaluate the technique, a new hybrid technique has been created where the data transmission is implemented from the beginning under MATLAB 2013a.

Results: The proposed technique is better than the existing ones since the remaining energy in the network is increased by $62 \%$ compared to normal nodes in MSEEC, $65 \%$ compared to advanced nodes in MSEEC and $70 \%$ compared to super nodes in MSEEC. The network lifetime was also enhanced by $70.8 \%$ compared to MSEEC.

Conclusion: The proposed protocol was found to be superior based on the average residual energy. This paper proposes an efficient routing mechanism towards the energy efficient network.

Originality: Through this research, a novel version of MSEEC protocol is carried out using the TABU search mechanism to generate the functions of two neighbourhoods to detect the optimum path with the aim of maximizing the network lifetime in an area of $200 \times 200 \mathrm{~m}^{2}$.

Limitations: The lack of other routing techniques falls under swarm intelligence.

Keywords:WSN, MSEEC routing protocol, TABU search, Throughput, and Energy efficiency.

\section{Resumen}

Introducción: Este artículo es el resultado de la investigación "Protocolos de enrutamiento energéticamente eficientes en la red de sensores inalámbricos: examine el impacto de los protocolos de enrutamiento M-SEEC en la vidaútil de WSN con un protocolo de enrutamiento de optimización TABU energéticamente eficiente" desarrolladoen el IKG, Punjab Technical University, India en 2019.

Problema: La tarea de encontrar y mantene rrutas en WSN no es trivial ya que las restricciones de energía y los cambios repentinosen el estado de los nodos causan cambios frecuentes e impredecibles.

Objetivo: El objetivo de este trabajo es proponer un protocoloheterogéneo de eficiencia energética con la ayuda de una técnica metaheurística híbrida.

Metodología: en la técnica metaheurística híbrida, se seleccionó la ruta más corta y los datos se enviaron al sumidero en un período de tiempo mínimo, ahorrando energía y haciendo que la red sea más estable. Para evaluar la técnica, se ha creado una nueva técnica híbrida donde la transmisión de datos se implementa desde el principio en MATLAB 2013a.

Resultados: La técnica propuesta es mejor que las existentes, ya que la energía restante en la red aumenta en un $62 \%$ encomparación con los nodos normales en MSEEC, el 65\% encomparación con los nodos avanzados en MSEEC y el 70\% encomparación con los nodos en MSEEC. La vidaútil de la red también se mejoróen un $70.8 \%$ encomparación con MSEEC.

Conclusión: se encontró que el protocolo propuesto era superior en función de la energía residual promedio. Este documento propone un mecanismo de enrutamiento eficiente hacia la red de energía eficiente. 
Originalidad: a través de esta investigación, se lleva a cabo una nueva versión del protocolo MSEEC utilizando el mecanismo de búsqueda TABU para generar las funciones de dos vecindarios para detectar la rutaóptima con el objetivo de maximizar la vidaútil de la red en un área de $200 \times 200 \mathrm{~m} 2$.

Limitaciones: La falta de otras técnicas de enrutamiento cae bajo inteligencia de enjambre.

Palabras clave: WSN, protocolo de enrutamiento MSEEC, búsqueda TABU, rendimiento y eficiencia energética.

\section{Resumo}

Introdução: Este artigo é o resultado da pesquisa "Protocolos de roteamento de eficiência energética em sensores sem fio rede: Examine o impacto dos protocolos de roteamento M-SEEC no tempo de vida de RSSF com um TABU energeticamente eficiente protocolo de roteamento de otimização "desenvolvido no IKG, Punjab Technical University, Índia em 2019.

Problema: A tarefa de encontrar e manter rotas em RSSFs não é trivial desde as restrições de energia e súbita mudanças no status do nó causam mudanças frequentes e imprevisíveis.

Objetivo: o objetivo deste artigo é propor um protocolo heterogêneo de eficiência energética com a ajuda de uma técnica meta-heurística híbrida.

Metodologia: Na técnica meta-heurística híbrida, a rota mais curta foi selecionada e os dados encaminhados para a pia em um intervalo de tempo mínimo, economizando energia e tornando a rede mais estável. Para avaliar o técnica, uma nova técnica híbrida foi criada onde a transmissão de dados é implementada a partir do começando em MATLAB 2013a.

Resultados: A técnica proposta é melhor do que as existentes uma vez que a energia restante na rede é aumentou $62 \%$ em comparação com nós normais em MSEEC, $65 \%$ em comparação com nós avançados em MSEEC e $70 \%$ em comparação com supernós em MSEEC. A vida útil da rede também foi aprimorada em 70,8\% em comparação com o MSEEC.

Conclusão: 0 protocolo proposto foi considerado superior com base na energia residual média. Este artigo propõe um mecanismo de encaminhamento eficiente para a rede com eficiência energética.

Originalidade: por meio desta pesquisa, uma nova versão do protocolo MSEEC é realizada usando a busca TABU mecanismo para gerar as funções de duas vizinhanças para detectar o caminho ótimo com o objetivo de maximizando a vida útil da rede em uma área de $200 \times 200 \mathrm{~m} 2$.

Limitações: A falta de outras técnicas de roteamento se enquadra na inteligência do enxame.

Palavras-chave: WSN, protocolo de roteamento MSEEC, pesquisa TABU, throughput e eficiência energética.

\section{INTRODUCTION}

Routingis a testing issue in the structure of WSNs, can greatly conserve energy and can also improve the network's life [1], while heterogeneity in WSNs can enhance the quality and time. Here, information sent from the transmitting node to the receiving nodeby lessening the over-head and increasing the throughput is the primary aim of routing. Developing a routing technique for WSNs is extremely critical. The realization of power saving to attain the green networking is the main objective of this paper. 
Many energy efficient clustering techniques for WSNs were introduced in the past such as SEEC, MSEEC [2] and CBCCP [3] ones, but these studies have not scrutinized the proper arrangement of the nodes to make the protocol more energy efficient and stable $[4,5]$. In the literature of MSEEC, there exists a lack of study to investigate the proper arrangements of different nodes viz. normal, super and advanced nodes and put forward an innovative routing scheme. In order to overcome this limitation, we address the case ofa network formation model which is deployed in the network. This launches the heterogeneity feature in the network and makes it more extensible. After that, a cluster formation procedure is introduced which depends upon the higher energy factor of the node and makes the network smooth on the way to WSN. On the contrary, a data transmission procedure is executed, which uses a novel approach towards clustering and routing via the TABU search mechanism for the optimization of energy parameters. The simulation results of this scheme aremore lithe and efficient compared to traditional WSNs [6-8].

Our contribution to this work can be summarised in the following order:

1. Network formation for the deployment of nodes is mentioned here. This structure has a network scalability feature and extends up to the $500 \mathrm{~m} \times 500 \mathrm{~m}$ level. For energy efficient communication, direct communication between the Normal Node (NN) and Super Node (SN) and alsobetweenSNand AdvancedNode (AN) is provided.

2. Consideration to the optimization problem in the proposed scheme with respect to load balancing and energy consumption for the implementation of an effective and scalable network. Thus, TABU-MSEEC is proposed under the influence of cluster formation and data transmission to solve the optimization dilemma. This approach is related to the implementation of the green network.

3. With extensive simulations using a random placement of sensor nodes, the suggested technique outperforms the traditional WSN schemes and are observed to be progressively supported for different applications of WSN.

\subsection{The proposed scheme is as follows:}

In this convention, NNs, ANs and SNsare utilized depending on their underlying initial energy. ANs have a times and SNs have $\beta$ times more energy than the NNs. The members of the cluster will send information to advanced and super node's cluster heads. After receiving the frames from the cluster member, the aggregation operation 
is performed to reduce the excessinformation.From that point onward, the information will be sent to the sink.The novelapproach to this paper is with regards to cluster formations for sensor nodes and data transmission procedures to reduce power consumption and to improve the lifetime of the system. The procedure comprises two stages: during the first stage, the cluster formation is made on the basis of the average residual powerin the node. The average residual energy ofthe Cluster Head $(\mathrm{CH})$ node is more prominent than the residualpower in the node in the system and in the second stage a 2-opt method is generated using the TABU search mechanism, which is a noteworthy criterion for routing. In this work, MSEEC protocol using the TABU search mechanism has been recommended which is a strategy with a more elevated heuristic quality for taking care of optimization issues. It can discover the ideal and close ideal answer for issues. Lots of studied have proposed routing techniquesfor saving nodal energy and improving the routing in WSNs. In this work,we address the matter of routing in WSNs utilizing the TABU search with the aim of maximizing the system lifetime. Initially, a new MSEEC protocol using the TABU search for routing in WSNs with the aim of maximizingsystem lifetime in networks of the order of $200 \mathrm{~m} \times$ $200 \mathrm{~m}$ is proposed.

The rest of the manuscript is in the following order: Section 2 examines the related work. Methodology has been described in Section 3.Section 4 shows thenetwork and procedures utilized.Section 5 depicts the results and discussion. Finally, Section 6 concludes the paper with future directions.

\section{RELATED WORK}

The available studies have discussed the applications and limitations of the networks. It has also given basic ideas of the functioning of the routing mechanisms and optimum low energy framework of the sensor nodes.

Vijayalakshmi et al. [9] have discussed the identification of optimum paths for routing that enhancethe life-time and decrease the power that is consumedby the network. Results showthat the efficiency of the TABU-PSO is increased by improving the formation of cluster heads, the ratio of active nodes and decreasing therate of mean packet loss, but in the paper the parameters are limited depending on the formation of network chosen. Kaur et al. [10] have proposed a hybrid data aggregating technique known as ACO/PSO,which improves the aggregation of data between the clusters. It is a tree-based algorithm where the selection of $\mathrm{CHs}$ iscompletely dependent upon the remaining nodes' energy. The proposed protocol has improved the life of 
theWSN over the other techniques but the author has failed to improve the area scalability as the size of network is so small.

Shankar et al.[11]haveexhibited ahybrid approach of a HAS \& PSO algorithm for providing better energy efficient cluster heads. These algorithmshaveshown anincrease in residual energy by $83.89 \%$ and throughput by $29 \%$ when compared tothe PSO algorithm. However, other meta-heuristic optimization techniques make better improvement over the network. Amuthan et al.[12] have reviewed the meta-heuristic techniques which are applied on combinatorial problems. This technique relieves local search methods from the local optima problem and finds the solution from a single point which is fitted in all the aspects of computer science including VANET, software development effort estimation etc, but has not been implemented with TABU. V.Raghavendranet al.[13] have portrayed the system routing research is Swarm Intelligence (SI) which links to the complex behaviour which emerges from exceptionally straightforward individual conduct and communication that is seen naturally, particularly with social flies, for example, honey bees, ants and so forth. Every individual has little knowledge and pursues the essential guidelines utilizing nearby data adjusted from nature. Ants directing is an essential instrument from SI and gives a proficient arrangement. Fifi et al.[14] exhibited the two energy-effective grouping convention, which utilized the ideal number of energetic nodes that accomplishes the base energy utilization for the system. The M-SEEC is a heterogeneous convention and drags out the soundness time frame, expands the energy effectiveness or more normal throughput.

Tandon, Ravi et al. [15]have devoted their efforts to progressively bunched heterogeneous sensor systems. They uncovered that the presented heterogeneity aware conventions could not disperse the utilization of energy consistently. The paper has proposed Cluster Re-election Protocol (CRP),that is aware of heterogeneity and upgrades the system dependability time over prevailing conventions. Shilpaet al.[16] proposed an energy balanced cluster head selecting strategy based on QoSfor WSN, which provides the weight selection method of $\mathrm{CH}$ known as Cluster-Chain Weight Metric approach (CCWM) for improving theeffectiveness of the entire network. With this approach the conservation of energy of sensors and load balancing takes place. Our objective in this paper is to select appropriate cluster headsby enhancing the quality of routing in HWSNs by lessening the general energy utilization, expanding the security time of the system and extending the system lifetime. The summary of work performed by various researchers in the past is given below: 
Table 1. Brief study of related work

\begin{tabular}{|c|c|c|c|}
\hline Author/Year & Title & Technique Discussed & Contribution \\
\hline $\begin{array}{l}\text { Vijayalakshmi } \\
\text { [2018] }\end{array}$ & $\begin{array}{l}\text { A multi objective TABU particle } \\
\text { swarm optimization for effective } \\
\text { cluster head selection in WSN }\end{array}$ & $\begin{array}{l}\text { Identification of optimum } \\
\text { paths for routing that enhance } \\
\text { the life-time and decreases the } \\
\text { power that is consumed by the } \\
\text { network }\end{array}$ & $\begin{array}{l}\text { Enhances the network } \\
\text { lifetime }\end{array}$ \\
\hline Kaur [2018] & $\begin{array}{l}\text { Hybrid meta-heuristic optimiza- } \\
\text { tion-based energy-efficient proto- } \\
\text { col for wireless sensor networks. }\end{array}$ & $\begin{array}{l}\text { Tree based algorithm where } \\
\text { the selection of } \mathrm{CH} \text { is basedon } \\
\text { the remaining node's energy. }\end{array}$ & $\begin{array}{l}\text { Improve the data ag- } \\
\text { gregation technique. }\end{array}$ \\
\hline Shankar [2016] & $\begin{array}{l}\text { Hybrid HSA and PSO algorithm } \\
\text { for energy efficient cluster head } \\
\text { selection in wireless sensor } \\
\text { networks. }\end{array}$ & Energy efficient cluster head. & $\begin{array}{l}\text { Enhancement in } \\
\text { throughput and overall } \\
\text { network lifetime. }\end{array}$ \\
\hline Amuthan [2016] & $\begin{array}{l}\text { Survey on TABU search me- } \\
\text { ta-heuristic optimization }\end{array}$ & $\begin{array}{l}\text { Relieved local search method } \\
\text { from local optima problem } \\
\text { and found solution. }\end{array}$ & $\begin{array}{l}\text { Improvement in VA- } \\
\text { NET, software design } \\
\text { effortestimation. }\end{array}$ \\
\hline $\begin{array}{l}\text { V.Raghavendran } \\
\text { [2013] }\end{array}$ & $\begin{array}{l}\text { Intelligent routing techniques for } \\
\text { mobile ad hoc networks using } \\
\text { swarm intelligence. }\end{array}$ & $\begin{array}{l}\text { Routing research with Swarm } \\
\text { Intelligence techniques. }\end{array}$ & Honey bees and ants \\
\hline Fifi [2014] & $\begin{array}{l}\text { Multi-level stable and ener- } \\
\text { gy-efficient clustering protocol in } \\
\text { heterogeneous WSN. }\end{array}$ & MSEEC protocol & $\begin{array}{l}\text { Expands the energy } \\
\text { effectiveness }\end{array}$ \\
\hline Tandon [2013] & $\begin{array}{l}\text { Cluster head Re-election Protocol } \\
\text { for heterogeneous wireless sen- } \\
\text { sor networks }\end{array}$ & Selection of Cluster Head $(\mathrm{CH})$ & Cluster Re-election. \\
\hline Shilpa [2014] & $\begin{array}{l}\text { An energy balanced QoS based } \\
\text { cluster head selection strategy } \\
\text { for WSN }\end{array}$ & $\begin{array}{l}\text { Weight selection method } \\
\text { applied. }\end{array}$ & $\begin{array}{l}\text { Enhancement in } \\
\text { network's lifetime by } \\
\text { appropriate } \mathrm{CH} \text {. }\end{array}$ \\
\hline
\end{tabular}

Source: own work

\section{METHODOLOGY}

In this system, the base station is static in nature and three unique kinds of nodes are utilisedwhich are NNs, ANs and SNs as explained previously. The base station's (BS) position is at the centre. A region of $A 2=M 2 \times M 2$ square meters over which nodes are consistently circulated aside from at the separation $\leq \mathrm{R} 1$. At first, SNs are situated at a place of separation R2 from the BS, and the ANs are situated at a place of separation $\mathrm{R} 1$ from the BS. The territory (M1 $\times \mathrm{M} 1)$ of the system is separated into a few equivalent clusters as the equivalent of the two-level heterogeneity network model, - the rest of the region $(\mathrm{M} 2 \times \mathrm{M} 2)-(\mathrm{M} 1 \times \mathrm{M} 1)$ is likewise partitioned into a few equivalent groups as indicated by the quantity of SNs. Every sensor network goes about as a cluster head and is in charge of its group. NNs are conveyed haphazardly in every group. The total clusters and their heads do not get altered during the life of the system. The 
clusters transmit the information stored in the sensors to the $\mathrm{CHs}$. Once a $\mathrm{CH}$ gets information outlines from the clusters, the collected information is evaluated to eliminate any excess information. At that point, $\mathrm{CH}$ s transmit the collected information to the BS. Although a static environment is good, such type of environment is failed in heterogeneous conditions because all sensor nodes are fixed;hence it is an energy efficient protocol but it suffers from the heterogeneity of a routing protocol. If the Super Node $(\mathrm{SN})$ which acts as a Cluster Head $(\mathrm{CH})$ dies or fails, the whole network will collapse.If a Super Node dies, then a Normal Node will directlycommunicate with an Advanced $\operatorname{Node}(\mathrm{AN})$ and energy consumption will be high which will reduce the network lifetime of a network; the whole network is Static and it also causes flooding at the sink or base station.

\subsection{Network Model}

An energy-efficient communication environment has been formalised as illustrated in Figure 1. The network consists of the three unique kinds of nodeswhich areNNs, SNs and ANs. One Base Station (BS) is used which is static in nature and positioned centrally in the network. The position of SNs and ANs is fixed for the whole lifetime of the system but the position of NNs is changed after every round. The number of ANsis $8 \%$ of the overall nodes. Similarly, the SNs are $8 \%$ of total nodes in the system. $M_{A N}$ characterises the part of all nodes that have a times $(\alpha=4)$ more energy than the NNs, known asadvancednodes, and $M_{S N}$ is the bit of all nodes having $\beta$ times $(\beta=3)$ more energy than the NNsand these are known as SN. The rest of the nodes haveinitial energy as $\mathrm{E}_{0}$.

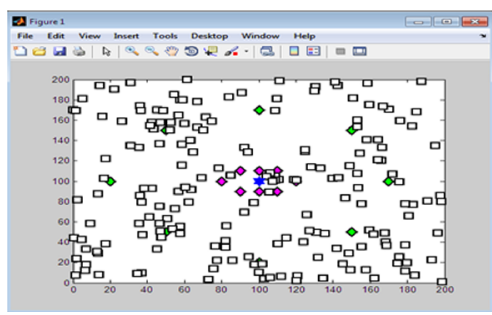

Figure 1. (a)Scenario of static nodes
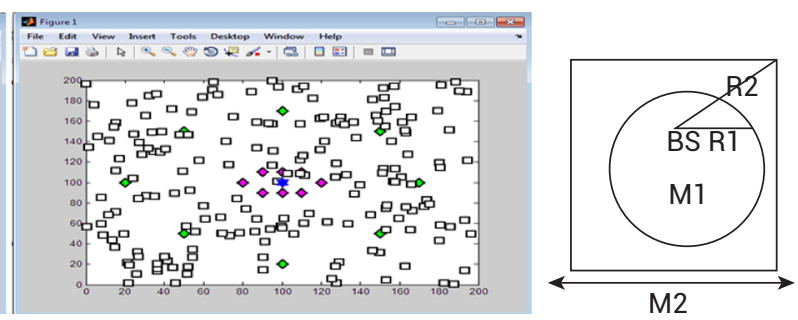

Figure 1. (b) Scenario of moving nodes

Source: own work

Figure 1(a) represents the networking model of the Enhanced MSEEC protocol, in which the base station is stationary and normal nodes are also static. In Figure 1(b) the nodes are changed after each round and SNs are located at a distance R2 
contingent with the base station and the ANs are located at a distance of R1 contingent with the base station.

\subsubsection{Energy required for the Network}

The nodes must be identified for evaluating the entire energy of heterogeneous systems with three levels. $M_{A N}$ of ANs has an initial energy of $(1+a) E_{0}$. Similarly, $M_{S N}$ of SN's has an initial energy of $(1+\beta) E_{0}$ and $n 1$ of $N N$ hasapreliminary energy of $E_{0}$. So the entirepreliminary energy required is

$$
E_{\text {total }}=\text { n. } E_{0}+\text { MAN. }(1+\alpha) \cdot E_{0}+\operatorname{Msn} \cdot(1+\beta) \cdot E_{0}(1)
$$

In this manner, the three-level M-SEEC has $\left(a \cdot M_{A N}+\beta . M_{S N}\right)$ times more energy.

\subsubsection{Total quantity of rounds in the network}

It is necessary to compute the total quantity of rounds in the lifetime of the network for all three kinds of node for evaluating the required energy of that system.In the following equation, $E_{\text {total }}$ describes the entire energy in the WSN and $E_{\text {total }}$ denotes the consumed energy in the WSNfor every individual round. Hence, Rounds ${ }_{\text {AN }}$, Rounds SN and Rounds ${ }_{N N}$ can be evaluated by following equation

$$
\begin{aligned}
& \text { Rounds }_{\mathrm{AN}}=\left(\frac{E_{\text {total }}}{E_{\text {round }}}\right)_{\mathrm{AN}} \\
& \text { Rounds }_{\mathrm{SN}}=\left(\frac{E_{\text {total }}}{E_{\text {round }}}\right)_{\mathrm{SN}} \\
& \text { Rounds }_{\mathrm{NN}}=\left(\frac{E_{\text {total }}}{E_{\text {round }}}\right)_{\mathrm{NN}}
\end{aligned}
$$

\section{NETWORK AND PROCEDURES UTILIZED}

To achieve the desired objectives, a different kind of network and several algorithms are required. A brief explanation about network implemention and procedures utilized in this work have been mentioned below: 


\subsection{Improvised Energy Efficient TABU Optimization Routing Protocol}

In the first case, an improvised TABU optimization routing protocol that has high energy efficiency has been proposedfor WSN in the presence of node heterogeneity with the routing done by TABU search in the stable environment. In this, the threekinds of nodes areon the basis of their energy value in the initial stage. The position of ANs and SNs are fixed but the position of NNs is not fixed. $M_{S N}$, which represents the super node, is the ratio of the nodes having a times higher energy than NNs to the total nodes. The rest of the nodeshave energy $E_{0}$. $P=p 1+p 2$ where $p 1$ is the overall number ofNNslinked to ANs and p2 is the overallNNslinked to SNs.The overall energy of the triple layered networks is represented by:

$$
\mathrm{E}_{\text {total }}=\mathrm{p} \cdot \mathrm{E}_{0}+\mathrm{M}_{\mathrm{AN}} \cdot(1+\alpha) \cdot \mathrm{E}_{0}+\mathrm{Msn} \cdot(1+\beta) \cdot \mathrm{E}_{0}
$$

Therefore, the three-level M-SEEC has $\left(a \cdot M_{A N}+\beta \cdot M_{S N}\right)$ times more energy.

Lemma 1: In a $Z$ * Z network with normal nodes, advanced nodes and super nodes, the best results are obtained when the energy value given is in the ratio of 1:3:4, meaning

$$
\begin{aligned}
& A N=3 * N N(\text { Normal Node) } \\
& S N=4 * N N(\text { Normal Node) }
\end{aligned}
$$

Proof: The results are provenby simulating the different energy of nodes in the ratio of 1:3:4. This means that the ANs have an energy thricethat of NNs and SNS havean energy four times more than that of NNs. Simulations are performed on 200 nodes on a 200×200 network respectively considering two parameters which are "First Node Dead"(FND) and "Last Node Dead"(LND).

Lemma 2: A node is something belonging to a cluster that is either a member of head.

Proof: As theTABU-MSEEC protocol is well spread across and hence has a good chance to select the $\mathrm{CH}$. The node may be designated as a $\mathrm{CH}$ only when the average remaining-energy of a $\mathrm{CH}$ is higherthan the remaining nodes in the WSN. Initially the 
SN will act as a $\mathrm{CH}$,but for any hardware or network failure, the node having more remaining energywill act as a $\mathrm{CH}$ and the other nodes will be the members.

Lemma 3: Data aggregating and clustering techniques are the top approaches for conserving energy in networks.

Proof: It is assumed that the transferinitiated from the upper-left corner to its opposite corner without any clustering technique and this means transferring directly.

Energy gain may be considered as the difference between the power consumed by transferring directly and power consumed by clustering technique.

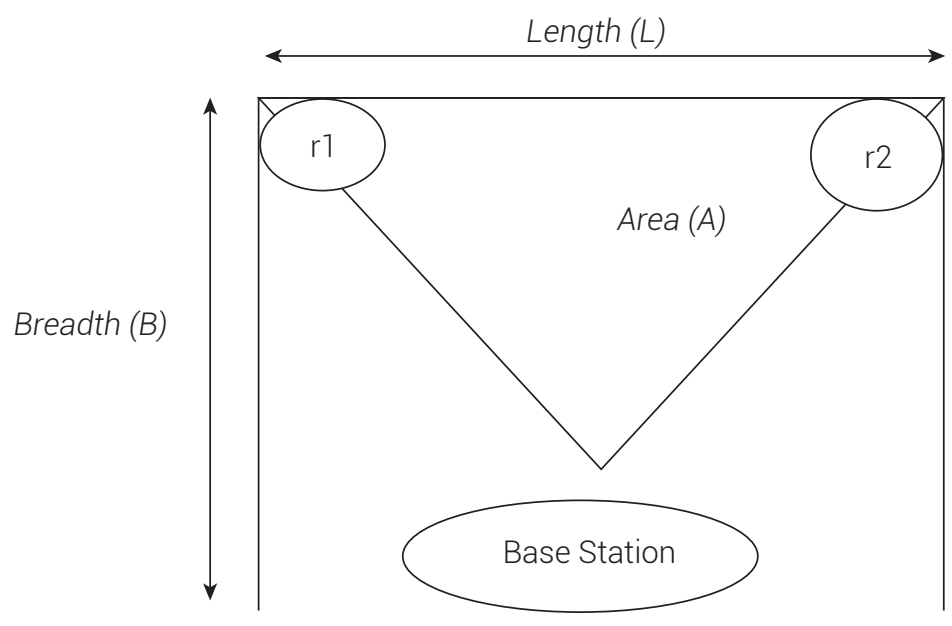

So,

$$
\text { Energy }_{\text {gain }}=E_{\text {direct_trans }}-E_{\text {clustering }}
$$

The nodes are spread in the network in a random manner and every group has a cluster head.

Which means, Energy ${ }_{\text {gain }>0}$

If

$$
\text { No of nodes }>2 \sqrt{2}(\text { Length } * \text { Breadth }) A_{\text {Length }} \times A_{\text {Breadth }}
$$

$$
\text { AsLength * Breadth }>>A_{\text {Length }} \times A_{\text {Breadth }}
$$

The optional length of the path from the node in uppermost cell to the bottommost cell is $\sqrt{L^{2}+B^{2}}$ by using Euclidian distance. 
In case of clustering, the path deviates by the $2 \sqrt{A_{\text {Length }}^{2}+B_{\text {Breadth }}^{2}}$ from the optimum path $2 A_{\text {Breadth. }}$ So optimum path for breadth is

$$
S u b_{\text {Optional }}=\sqrt{A_{\text {Length }}^{2}+4 A_{\text {Breadth }}^{2}} \times \sqrt{L^{2}+B^{2}} \square 2 A_{\text {Breadth }}
$$

The meanpower consumed by the nodes in every cluster is represented by

$$
\text { Nodes }_{\text {average }}=\left(\text { no of nodes } \times A_{\text {Length }} \times A_{\text {Breadth }}\right) 2 L B
$$

$E_{d}$ is the power consumedby the entire nodes in the cell for transmittingthe information along the path $\sqrt{L^{2}+B^{2}}$

So,

$$
E_{d}=\left(\text { no of nodes } \times A_{\text {Length }} \times A_{\text {Breadth }}\right) \square 2 L B \times \sqrt{L^{2}+B^{2}}
$$

$E_{c}$ is the power consumed by the entire nodes in the cluster for transmitting thedata to the respective $\mathrm{CH}$ and from $\mathrm{CH}$ to the destination.

Total no of $\mathrm{CH}$ is $\mathrm{N}_{\text {totalCH }}$

$$
\begin{aligned}
& E_{C}=N_{\text {totalCH }}\left(\left(\left(\text { no of nodes } \times A_{\text {Length }} \times A_{\text {Breadth }}\right) \square 2 L B\right)-1\right) \times A_{\text {Breadth }}+2 B \\
& E_{c} \doteq\left(\left(N_{\text {totalCH }} \times \text { no of nodes } \times A_{\text {Length }} \times A_{\text {Breadth }}^{2}\right) \square 2 L B\right)+2 B
\end{aligned}
$$

By substituting the values:

$$
\begin{aligned}
& \text { Energy } y_{\text {gain }}=E_{\text {direct_trans }}-E_{\text {clustering }} \\
& =\left(\text { no of nodes } \times A_{\text {Length }} \times A_{\text {Breadth }}\right) \square 2 L B \times \sqrt{L^{2}+B^{2}}-\left(\left(N_{\text {totalCH }} \times\right.\right. \\
& \text { no of nodes } \left.\left.\times A_{\text {Length }} \times A_{\text {Breadth }}^{2}\right) \square 2 L B\right)-2 B>0 \\
& \text { AsEnergy }_{\text {gain }>0}
\end{aligned}
$$

Therefore, 
$=\left(\right.$ no of nodes $\left.\times A_{\text {Length }} \times A_{\text {Breadth }}\right) \square 2 L B \times \sqrt{L^{2}+B^{2}}-\left(\left(N_{\text {totalCH }} \times\right.\right.$ no of nodes $\left.\times A_{\text {Length }} \times A_{\text {Breadth }}^{2} \square 2 L B\right)>0$

By taking no of nodes $\left.\times A_{\text {length }} \times A_{\text {Breadth }}\right) 2 L B$ as common

$$
\begin{aligned}
= & \text { no of nodes } \left.\times A_{\text {Length }} \times A_{\text {Breadth }}\right) \square 2 L B\left(\left(\sqrt{L^{2}+B^{2}}-\right.\right. \\
& \left.\left.\left(N_{\text {totalCH }} \times A_{\text {Breadth }}\right)\right)\right)>2 B \\
= & n>2 B\left(2 L B / A_{\text {Length }} \times A_{\text {Breadth }}\left(\sqrt{L^{2}+B^{2}}-A_{\text {Breadth }}\right)\right. \\
= & n>4 L B^{2} \square\left(A_{\text {Length }} \times A_{\text {Breadth }}\left(\sqrt{L^{2}+B^{2}}-A_{\text {Breadth }}\right)\right)
\end{aligned}
$$

Since Length $>A_{\text {Breadth }}$ therefore, $\sqrt{L^{2}+B^{2}}>A_{\text {Breadth }}$

\subsubsection{Level of heterogeneity}

The level of heterogeneity is represented by the given formula that is

$$
\mathrm{R}_{\mathrm{i}-1}=\frac{\sqrt{2}}{0.765} \mathrm{R}_{\mathrm{i}-2}
$$

Where i denotes the heterogeneity level.

\subsubsection{Optimumcount of ANs}

The amount of power that is consumed at the time of single transferis expressed by following condition

$$
\mathrm{E}_{\mathrm{AN}}=\mathrm{n}_{\mathrm{A}} \cdot \mathrm{L} \cdot \mathrm{E}_{\mathrm{elec}}+\mathrm{n}_{\mathrm{A}} \cdot \mathrm{L} \cdot \mathrm{E}_{\mathrm{DA}}+\mathrm{L} \cdot \mathrm{E}_{\mathrm{elec}}+\mathrm{L} \cdot \mathrm{e}_{\mathrm{fs}} \cdot R 1^{2}
$$

Where $E_{D A}$ represents the data aggregation cost and $R 1$ represents the distance between advanced node and base station. The energy utilized by normal nodes is expressed by the following equation 


$$
\mathrm{E}_{\mathrm{NN}}=\mathrm{L} . \mathrm{E}_{\mathrm{elec}}+\mathrm{L} . \mathrm{e}_{\mathrm{fs}} \cdot d_{t O A N}^{2}
$$

Where $d_{t o \text { AN }}^{2}$ represents the distance between the normal node and advanced nodes.

The total power that is consumed at the time of a single transfer is expressed by the following condition

$$
\begin{aligned}
& \mathrm{E}_{\mathrm{Round}}=\mathrm{m}_{\mathrm{AN}}\left(\frac{n 1}{m_{A N}} \cdot L \cdot E_{\text {elec }}+\frac{n 1}{m_{A N}} \cdot L \cdot E_{D A}+L \cdot E_{\text {elec }}+L \cdot E_{f s} \cdot R 1^{2}+\right. \\
& \left.\frac{n 1}{m_{A N}} \cdot L \cdot E_{\text {elec }}+\frac{n 1}{m_{A N}} \cdot L \cdot E_{f s} \cdot d_{\text {to } A N}^{2}\right)
\end{aligned}
$$

After differentiating $\mathrm{E}_{\text {Round }}$ corresponding to $\mathrm{M}_{\mathrm{AN}}$ and comparing with zero, the optimumcount of advanced nodes is found to be

$$
\mathrm{m}_{\mathrm{AN} \mathrm{opt}}=0.7668 \sqrt{n 1}
$$

\subsubsection{Required energy for AN}

For computing the energy of ANs, the total life of a WSNis first calculated, which is the total of all rounds from beginning to end.

$$
\text { Rounds }_{\mathrm{AN}}=\left(\frac{E_{\text {total }}}{E_{\text {round }}}\right)_{\mathrm{AN}}
$$

and

$$
\text { Rounds }_{\mathrm{NN}}=\left(\frac{E_{\text {total }}}{E_{\text {round }}}\right)_{\mathrm{NN}}
$$

The value of an advanced node should be greater than that of normal nodes in each cluster 


$$
\alpha \geq\left[\frac{n_{A} \cdot \text { Eelec }+\mathrm{n}_{A} E_{D A}+E_{\text {elec }}+E_{f S} \cdot R 1^{2}}{E_{\text {elec }}+E_{f s} \cdot d_{\text {to } A N}^{2}}\right]-1
$$

\subsubsection{Optimal Number of SNs}

The amount of power that is consumed at the time taken for a single transfer is expressed by the following condition

$$
\mathrm{E}_{\mathrm{SN}}=\mathrm{n}_{\mathrm{S}} \cdot \mathrm{L} \cdot \mathrm{E}_{\mathrm{elec}}+\mathrm{n}_{\mathrm{S}} \cdot \mathrm{L} \cdot \mathrm{E}_{\mathrm{DA}}+\mathrm{L} \cdot \mathrm{E}_{\mathrm{elec}}+\mathrm{L} \cdot \mathrm{e}_{\mathrm{fs}} \cdot R 2^{2}
$$

Where $E_{D A}$ represents the data aggregation cost and $R 1$ represents the distance between advanced nodes and the base station. The energy utilized by normal nodes is expressed by the following equation

$$
\mathrm{E}_{\mathrm{NN}}=\mathrm{L} \cdot \mathrm{E}_{\mathrm{elec}}+\mathrm{L} \cdot \mathrm{e}_{\mathrm{fs}} \cdot d_{t O}^{2} C_{H}
$$

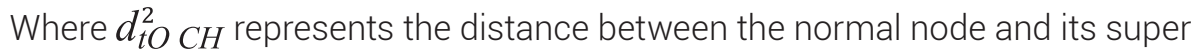
and advanced nodes.

The total power that is consumed at the time taken for a single transfer is expressed by the following condition

$$
\mathrm{E}_{\mathrm{Round}}=\mathrm{M}_{\mathrm{AN}}\left(E_{A N}+n_{A} \cdot E_{N N}+m_{S N} \cdot\left(E_{S N}+n_{S} \cdot E_{N N}\right)\right.
$$

After differentiating $E_{\text {Round }}$ with respect to $\mathrm{M}_{\mathrm{SN}}$ and equating with zero, the optimum count of super nodes found to be

$$
\mathrm{M}_{\mathrm{SN} \text { opt }}=0.7668 \sqrt{n 2}
$$

\subsubsection{Required energy for SN}

For computing the energy of advanced nodes, firstly calculate the total lifetime of a network which is the total of all rounds from beginning to end. 


$$
\text { Rounds }_{\mathrm{SN}}=\left(\frac{E_{\text {total }}}{E_{\text {round }}}\right)_{\mathrm{SN}}
$$

and

$$
\text { Rounds }_{\mathrm{NN}}=\left(\frac{E_{\text {total }}}{E_{\text {round }}}\right)_{\mathrm{NN}}
$$

The value of advanced nodes should be greater than that of normal nodes in each cluster

$$
\beta \geq\left[\frac{n_{S N} \cdot \text { Eelec }+\mathrm{n}_{S N} E_{D A}+E_{\text {elec }}+E_{f S} \cdot R 2^{2}}{E_{\text {elec }}+E_{f S} \cdot d_{\text {to } S N}^{2}}\right]-1
$$

\subsection{ALGORITHMS UTILIZED}

These are several algorithms/procedures developed and utilized to reach our objectives.These algorithms are given below:

\subsubsection{Network Formation Procedure}

The TABU-MSEEC model considers a structure made out of a predefined quantity of nodes placed discretionarily in a testing area. The entire group of nodes have a starting energy that is proportional to E0. In the proposed estimation, 3 stages are invoked. The first stage is a network formation procedure where the roles of different nodes are selected. The accompanying stage is the cluster formation procedure and this is where the clusters are formed. The last one is the data transmission procedure, where the routing is done via the process of theTABU algorithm.

Network Formation Procedure

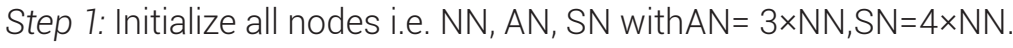

Step 2: The AN is situated at a location that is $\mathrm{R} 1$ units away from the BS.

$$
\begin{gathered}
\theta_{j}=\varnothing+(j-1) \times 360 / m_{A N} \\
\text { Where, } j=\left(1,2,3, \ldots \ldots . . m_{A N}\right) \\
\text { and } \varnothing=180 / m_{A N}
\end{gathered}
$$


Step 3: The $\mathrm{SN}$ is located at a position of distance $\mathrm{R} 2$ with respect to the remaining area(M2×M2)-(M1×M1).

Step 4: The normal nodes are randomly deployed.

\section{Algorithm for Network Formation Procedure}

\section{Begin}

Initialise $\mathrm{i}, \mathrm{i} \in \mathrm{N}$, where, $\mathrm{N}=\{\mathrm{NN}, \mathrm{AN}$ and $\mathrm{SN}\}$

Set value as,

$A N=3 * N N$

$\mathrm{SN}=4 * \mathrm{NN}$

Source $=$ NN (process will start from normal nodes)

Set position of $A N$ atdistance $R 1$ with respect to base station.

$\theta_{j}=\varnothing+(j-7) \times 360 / m_{A N}$

Where, $j=\left(1,2,3, \ldots \ldots . . m_{A N}\right)$

and $\varnothing=180 / \mathrm{m}_{\text {AN }}$

Set position of $\mathrm{SN}$ at distance $\mathrm{R} 2$ with respect to remaining area.

(M2×M2)-(M1×M1)

The NNsare deployed in a random manner in the network.

\section{End}

\subsubsection{Cluster Formation Procedure}

Once the network model is fixed, the next aim is to identify the cluster head from the entire network. A CH should be selected on the basis of their highest energy parameter. Since all the sensor nodes have extremely restricted energy, the $\mathrm{CH}$ must gather all the node data and after that, forward it to the sink; the rest of the energy of the node ought to be viewed while picking the $\mathrm{CH}$. Thechoosing process of the $\mathrm{CH}$ is as follows:

Cluster Formation Procedure

Step 1: As per the directions of the nodes in every locale, the focal point of locale's gravity is determined. This point $\left(X_{f}, Y_{f}\right)$ ought to be correspond with the slightest square and least separation of nodes in the network, and the following formula is used.

$$
\left(\mathrm{X}_{\mathrm{f}}, \mathrm{Y}_{\mathrm{f}}\right)=\min \sum_{i=1}^{N}\left[\left(x-x_{i}\right)^{2}+\left(y-y_{i}\right)^{2}\right]
$$

Where $\left(X_{f}, Y_{f}\right)$ is the direction of every node; 
Step 2: The distance between the nodes and its focal point of gravity is obtained by equation

$$
\mathrm{d}=\sqrt{\left.x_{c}-x_{i}\right)^{2}+\left(y_{c}-y_{i}\right)^{2}}
$$

Step 3:Compute the normal remaining power in the nodes of every group. Supposing $E_{i}$ is the preliminary energy of the node, thenthe power that is consumed by the node $\mathrm{E}(\mathrm{t})$ at time tis given by

$E(t)=\left(\right.$ Number $\left._{\text {s_packet }} * a\right)+\left(\right.$ Number $\left.{ }_{r_{\text {_packet }}} * \beta\right)$

Where, Number s_packet $_{=}$total packetstransmitted,

Number $_{\text {r_packet }_{\text {e }}}=$ total packets received

$(a, \beta) €$ range $[0,1]$

Now, $\mathrm{E}_{\mathrm{rem}}$ at time $\mathrm{t}$ is calculated by utilisingexpression

$E_{r e m}=E_{i}-E(t)$

Step 4: If the remaining energy of the nodes is more prominent than every node in the mean residual energy, then that node is chosen as the head. If not, then the next node is compared. A sensor node whose energy is more prominent than the mean remaining energy is identified as the $\mathrm{CH}$.

\section{Algorithm for Cluster Formation}

\section{Begin}

Initialise $\mathrm{i}, \mathrm{i} \in \mathrm{N}$, where, $\mathrm{N}=\{\mathrm{NN}, \mathrm{AN}$ and $\mathrm{SN}\}$

Set value as,

SP (Selection Parameter) = Average remaining energy of NNs / Residual energy of SNS

If $\mathrm{SP}<1$

Then $\mathrm{SN}$ will act as a $\mathrm{CH}$

Else $S P>1$

Then next super node will act as a $\mathrm{CH}$ on the basis of its residual energy.

The residual energy of the super node >average remaining energy of normal nodes

\section{Endif}

\section{End}




\subsubsection{Data Transmission Procedure}

In the TABU-MSEEC protocol, the TABU technique is employed in order to make the network more energy-saving. A cluster in the network is chosen on the basis of its energy parameter and these clusters gather details from their members and send it to the sink $[17,18]$. For the transmission phase, the TABU technique is used, which makes the network more methodical and reliable. In order to perceive the optimal solution,the initial solution is produced by the TABU search achievably and simultaneously.The inceptive solution becomes the best solution and the current solution is placed in the TABU list which is the memory list and is usedinorder to avert the cycling. The first selected element in the list is replaced by a novel oneif the existing list is already filled. The result of the TABU search,which is the current solution, is updated in the TABU list. Each time, the set of neighbours of the existing solution is obtained by performing neighbourhood techniquesand the neighbour with the maximum value is marked as the newer solution in the list; this is then accepted for the selection of the candidate solution, otherwise the solution having the subsequentmaximum number becomes the candidate.The rate of newer solution is related with the existing solution,otherwise, iterations are increased and the newly obtained solution is incorporated into the list and is then allocated as the newsolution for the next selection[19, 20].

Data TransmissionProcedure

By random generation, we choose the initial feasible solution, and we choose it to be the current solution.The TABU search algorithm is then applied in order toincrease the existing solution. Itis represented as a pack of $n$ routes which are $R 1, R 2, R 3, \ldots .$. $\mathrm{Rn}$, and the challenge here istoobtain the shortest,boosting the network lifetime and significantly reducing in energy consumption. Thesubsequent steps are as follows:-

Step1: A solution is represented by a sequence of randomly generated solutions and is searched in accordance with the constraints. Theobjective function is then calculated by utilizing the initial solution as the current solution.

Step 2: In order to producethe neighbourhood solutions, the 2 opt method is utilized which is performed by swapping the position of two randomly selected solutions. By doing so," $n *(n-1) / 2$ " sequences are generated. The framework is initiated with a randomly generatedpreliminary solution and travels from one neighbour to anotherwhile continuously altering the value of the objective functions. E.g., let the initial sequence be $(1,2, \ldots \ldots . . . . . b \ldots . . . n)$.After exchanging the positions of the two solutions, the newly obtained sequence will be $(1,2, \ldots . . . b, \ldots a, \ldots . n)$, which will become the new solution for every iteration in the list. 
Step 3: In accordance with the aspiration criteria, the neighbourhood solution is found and the current solution is then amended in the TABU list. If the solution is good when compared to the existing optimum solution, then it is updatedin the list and the solution is monitoredto verify if itis a TABU. If it is, then choose the next ideal solution and if it is not, then the existing oneis updated as the present solution and updated in the list.

The process of steps from 1 to 3 is repeated with a specific iterated step and the lastvalue of shortest route among the entire network is given as the output.

\section{Algorithm for Data Transmission}

\section{Begin}

Select a preliminary solution $\mathrm{i}$ in solution space.

Fix $i *=i$

$\mathrm{K}$ (Number of iteration) $=0$

Fix $\mathrm{K}=\mathrm{K}+1$ and create a subset $\mathrm{V}$ * of solution in $\mathrm{N}(\mathrm{i}, \mathrm{K})$

Where $\mathrm{N}$ = neighbouring solution (// Here, any of the TABU conditions are violated or minimum one aspiration condition hold)

Select the best $\mathrm{j}$ in $\mathrm{V}$ and seti $*$ I (// if new value is better than the previous one) Update TABU and aspiration criteria

If the condition is satisfied, then it is stopped

\section{Else}

Goto the next iteration

\section{Endif}

\section{End}

\section{RESULTS AND DISCUSSION}

In order to analyse the results of TABU-MSEEC,a MATLAB 2013a simulator is used for the implementation. In the network scenario, 200 nodes are placed of which eightANs and eightSNs are fixed and rest of the NNs are located in a random manner inside the area of $200 \times 200 \mathrm{~m}^{2}$.The position of the BS is fixed at $(100,100)$. Nodes are assumed to be dead when their energy parameters value is zero. For the evaluation, the radio energy model that was proposed byHeinzelman[21] is utilised. Results of MSEEC arerelated with TABU-MSEEC protocol.They are assessed on the basis of these parameterswhich are mentioned below in Table 4. 
Table 2. Simulation Parameter

\begin{tabular}{cc}
\hline Parameter & Value \\
\hline Size of Network & $200 \times 200$ \\
\hline Position of Base station & $100 \times 100$ \\
\hline Number of Nodes & 200 \\
\hline Probability(p) & $10 \%$ \\
\hline Preliminary Energy & 0.5 \\
\hline Energy of the transmitter & $0.05 \mathrm{pJ} / \mathrm{bit}$ \\
\hline Energy of the receiver & $0.05 \mathrm{pJ} / \mathrm{bit}$ \\
\hline Free space & $10 \mathrm{nj} / \mathrm{bit} / \mathrm{m}^{2}$ \\
\hline Multi-path & $0.0013 \mathrm{pJ} / \mathrm{bit} / \mathrm{m}^{4}$ \\
\hline
\end{tabular}

Source: own work

On applying the TABU search mechanism, the following results are obtained. For the simulation,the MATLAB 2013a tool is used for easy computing of results. All results were compared with the basic multi-level protocol which has high energy efficiency and stability. The performance metrics used in the results show that the proposed TABU based MSEEC protocol is stable for a longer time,has higher energy efficiency and higher throughput when compared to basic multi-level clustering protocols. For simulation, we analyse the results based on two conditions i.e. with static nodes and moving normal nodes with each round.

\section{Evaluation of MSEEC and TABU-MSEEC in terms of alive nodes}

It is the amount of individual types of nodes and also the aggregate amount of nodes which has not used their entire energy.This measurement demonstrates the entire lifespan of the system. All the more essentially, it providesa portion of the covered area of the system after some time. The FND refers to the initial deadnode in the rounds. This parameter gives details as to how stable the protocolis. The TABU-MSEEC has more stability than that of a MSEEC Protocol. The FND is delayed by 1450, 1950 and 3500 rounds in NN, AN and SN respectively. Also the LND is delayed by 100, 4200 and 5000 rounds in NN, AN and SN respectively. 


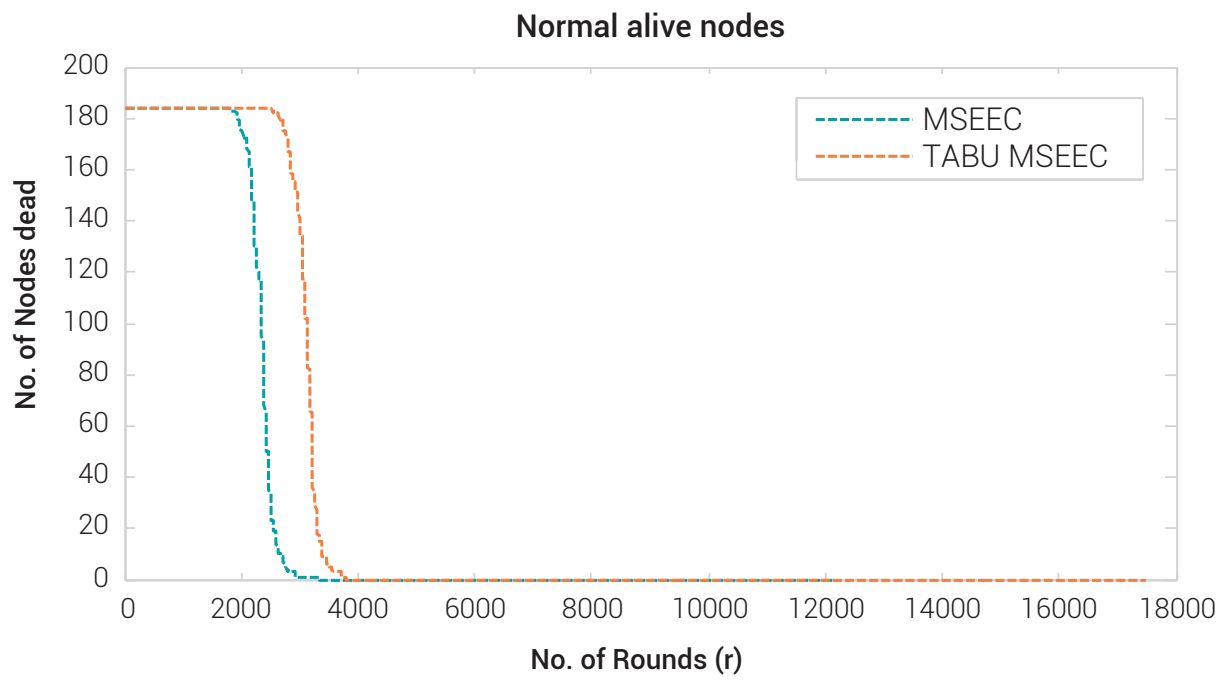

Figure 2. Normal alive node vs. rounds for 200 nodes in $200 \times 200$ network Source: own work

200 nodes are simulated in a 200×200 network for MSEEC and the proposed TABU-MSEEC protocol as seen in Figure 2. From the obtained results, theFND and LND are calculated. From the figure, it is observed that the value of FNDforMSEEC is 2050 and the value of LND for MSEEC is 3900. On the other hand,the value in the case of TABU-MSEEC is 3500 for FND and 4000 for LND.

Table 3. FND and LND of normal nodes

\begin{tabular}{cccc}
\hline Nodes & Protocol & FND & LND \\
\hline \multirow{2}{*}{ NN(Normal Node) } & MSEEC & 2050 & 3900 \\
\cline { 2 - 4 } & TABU- MSEEC & 3500 & 4000 \\
\hline
\end{tabular}

200 super alive nodes are simulatedin a 200×200 for MSEEC and TABU-MSEEC protocol as seen in Figure 3. From the obtained results, the FND and LND are calculated. From the figure, it is observed that the value of FND for MSEEC is 6050 and the value of LND in the case of MSEEC is 7800; on the other hand, the value in the case of TABU-MSEEC is 8000 for FND and 12000 for LND. 


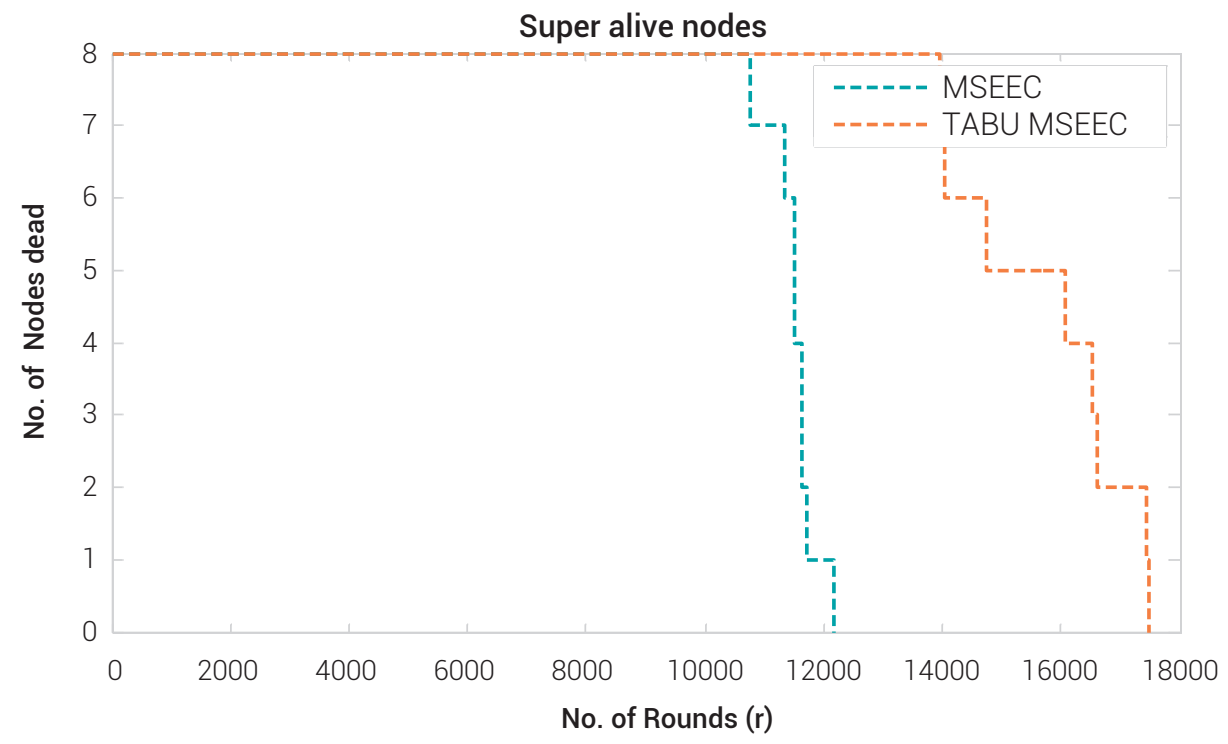

Figure 3. Super alive node vs. rounds for 200 nodes in $200 \times 200$ network Source: own work

Table 4. FND and LND of advanced nodes

\begin{tabular}{cccc}
\hline Nodes & Protocol & FND & LND \\
\hline \multirow{2}{*}{ AN(Advanced Node) } & MSEEC & 6050 & 7800 \\
\cline { 2 - 4 } & TABU- MSEEC & 8000 & 12000 \\
\hline
\end{tabular}

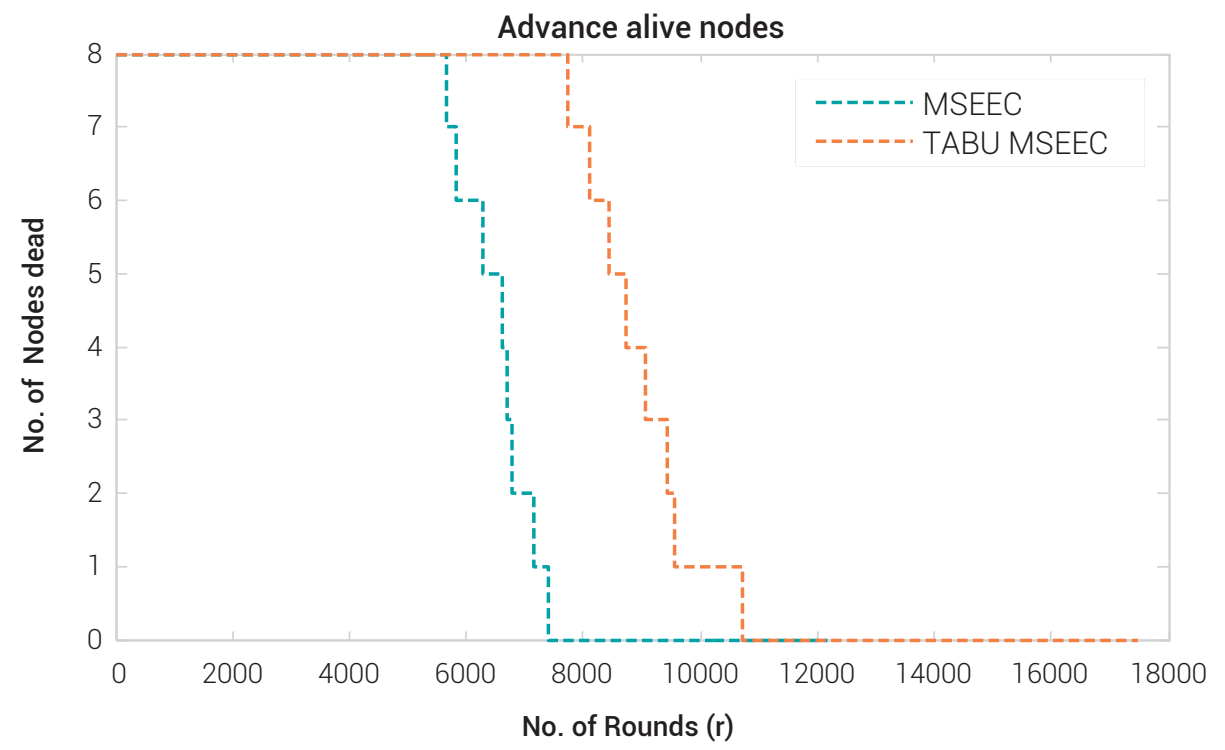

Figure 4. Advanced alive node vs. rounds for 200 nodes in $200 \times 200$ network Source: own work 
Similarly, 200 advanced alive nodes are simulated in a 200×200 network for MSEEC and the proposed TABU-MSEEC protocol as seen in Figure 4. From the obtainedresults,FND and LND are calculated. From the figure, it is observed that the value of FND for MSEEC is 11000 and the value of LND in the case of MSEEC is 12500; on the other hand, the value in case of TABU-MSEEC is 14500 for FND and 17500 for LND.

Table 5. Stability comparison for different protocol

\begin{tabular}{cccc}
\hline \multirow{2}{*}{ Nodes } & Protocol & FND & LND \\
\hline \multirow{2}{*}{ NN(Normal Node) } & MSEEC & 2050 & 3900 \\
\cline { 2 - 4 } & TABU- MSEEC & 3500 & 4000 \\
\hline \multirow{2}{*}{ AN(Advanced Node) } & MSEEC & 6050 & 7800 \\
\cline { 2 - 4 } & TABU- MSEEC & 8000 & 12000 \\
\hline \multirow{2}{*}{ SN(Super Node) } & MSEEC & 11000 & 12500 \\
\cline { 2 - 4 } & TABU-MSEEC & 14500 & 17500 \\
\hline
\end{tabular}

Source: own work

Hence, it may be concluded from the comparison in Table 1that the optimum results are obtained when the energy value of nodes is increasing. This also indicates that TABU-MSEEC has more valuable results than the MSEEC protocol.

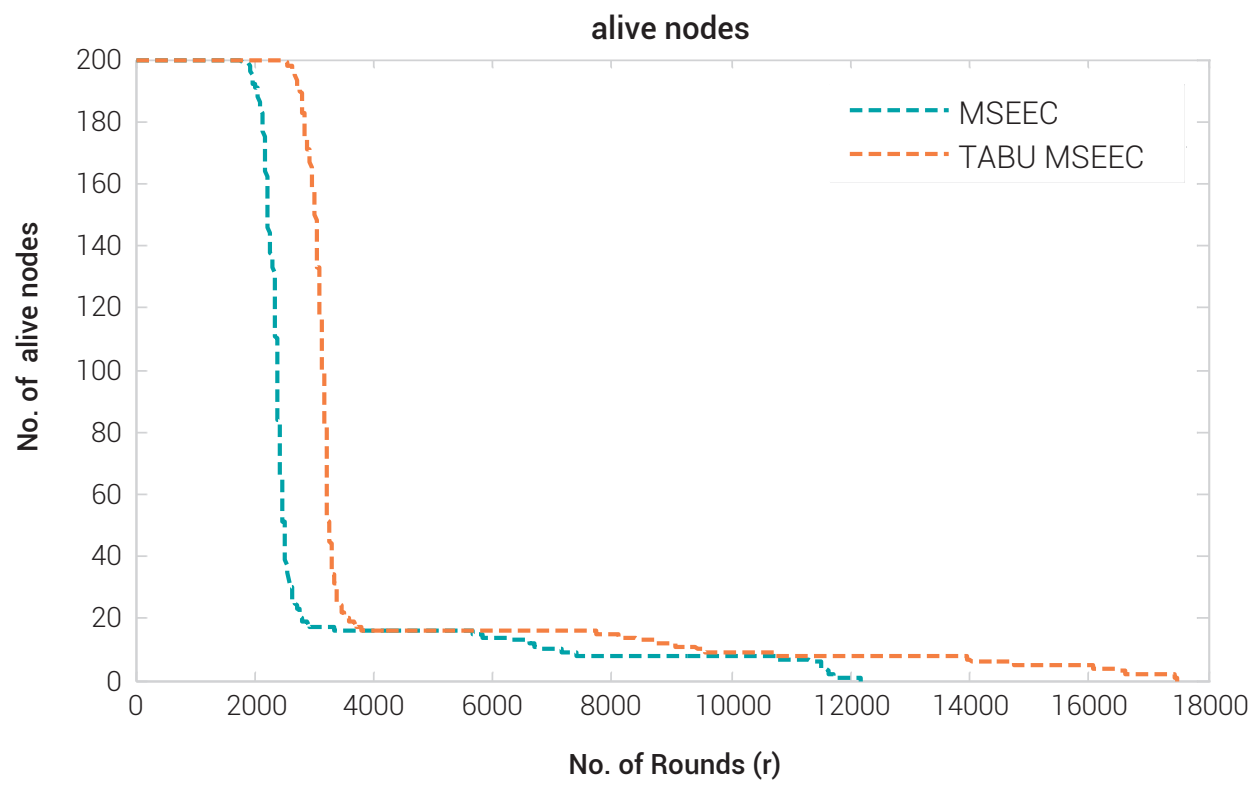

Figure 5. Total alive node vs. rounds for 200 nodes in $200 \times 200$ network Source: own work 
Figure 5 depicts the total nodes which are alive for all rounds. It is seen that the FND of MSEEC begins at around 2050 rounds, whereas LND begins at around 12050. Similarly, for TABU-MSEEC, FND begins at around 3050 rounds, whereas LND begins at around 17000: because the TABU takes time to find the best solution initially.

\section{Evaluation of MSEEC and TABU-M-SEEC in terms of dead nodes}

The performance of MSEEC and TABU-MSEEC protocol is also determined on another parameter; dead nodes. Here, the dead node parameter is calculated among NNs, ANs, SNsand the total nodes in the network.
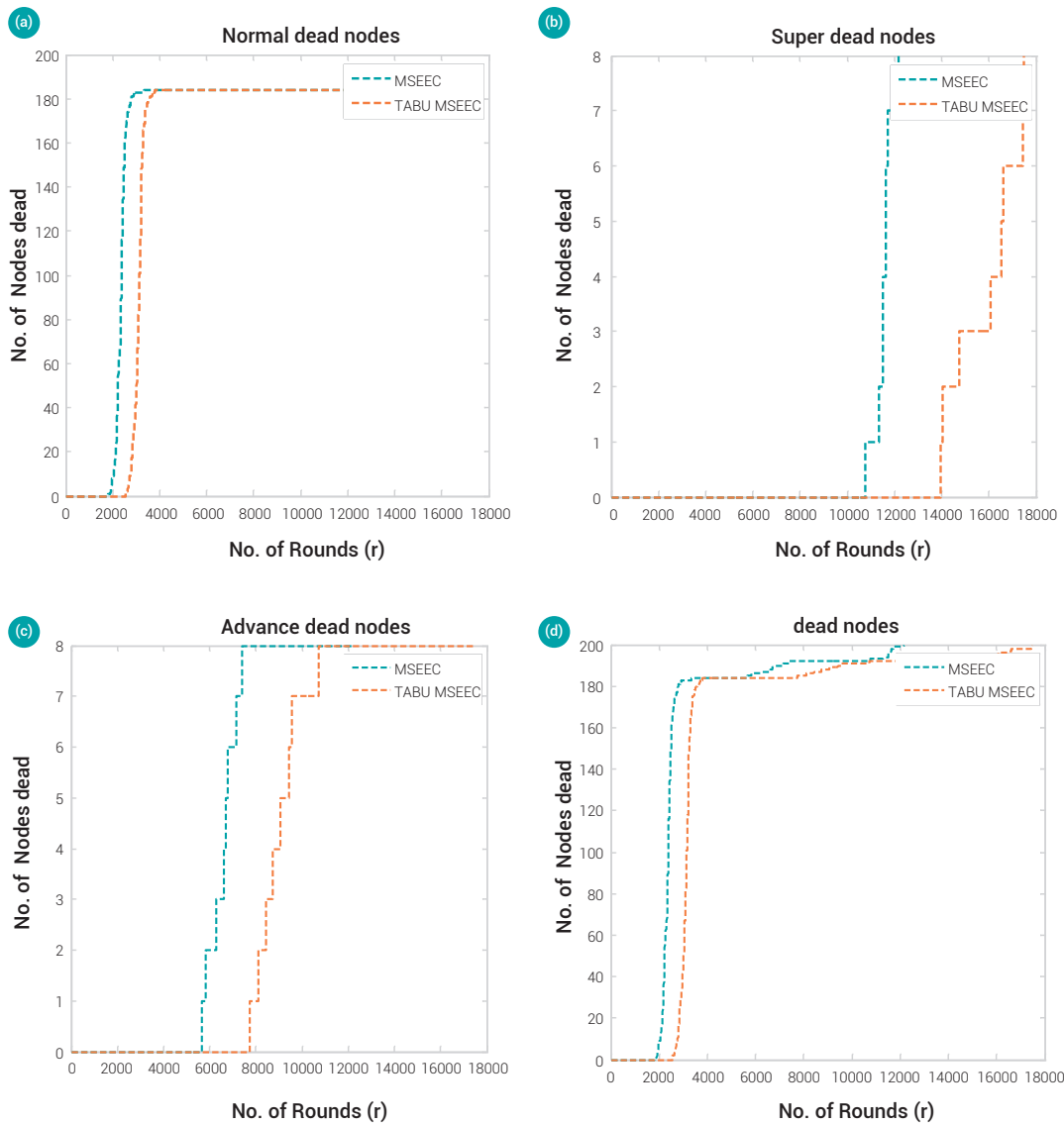

Figure 6.Number of dead nodes

Source: own work
(a) Normal dead node vs. rounds for 200 nodes in $200 \times 200$ network
(b) Super dead node vs. rounds for 200 nodes in $200 \times 200$ network
(c) Advanced dead node vs. rounds for 200 nodes in $200 \times 200$ network
(d) Total dead nodes vs. rounds for 200 nodes in $200 \times 200$ network 
Figure 6represents the behaviour of dead nodes in a detailed manner for MSEEC and TABU-MSEEC routing protocols. It is seen that TABU-MSEEC works better than MSEEC. In MSEEC, the death of the first node begins after 2000 rounds, whereas for TABU-MSEEC it begins after 2200 rounds for normal nodes. In the case of super nodes,the death of the first node begins after 10050 rounds in MSEEC, whereas for TABU-MSEEC it begins after 14000 rounds. For advanced nodes, the death of the first node begins after 5900 rounds, whereas for TABU-MSEEC it begins after 6500 . This is because the advanced nodes and super nodes lose their lifeslower than the normal nodes.

\section{Evaluation of MSEEC and TABU-MSEEC in terms of throughput}

Throughput is the amount of data packets which are obtained at the sink. It is considered as the totaldata which is transferred through the network, the total data sent from ANs or SNs to the BS. It can also be considered as the total data sent from the NNs to the ANs and SNs.When the proposed protocol is compared with existing protocol, it can be seen that the proposed protocol shows improved throughput.

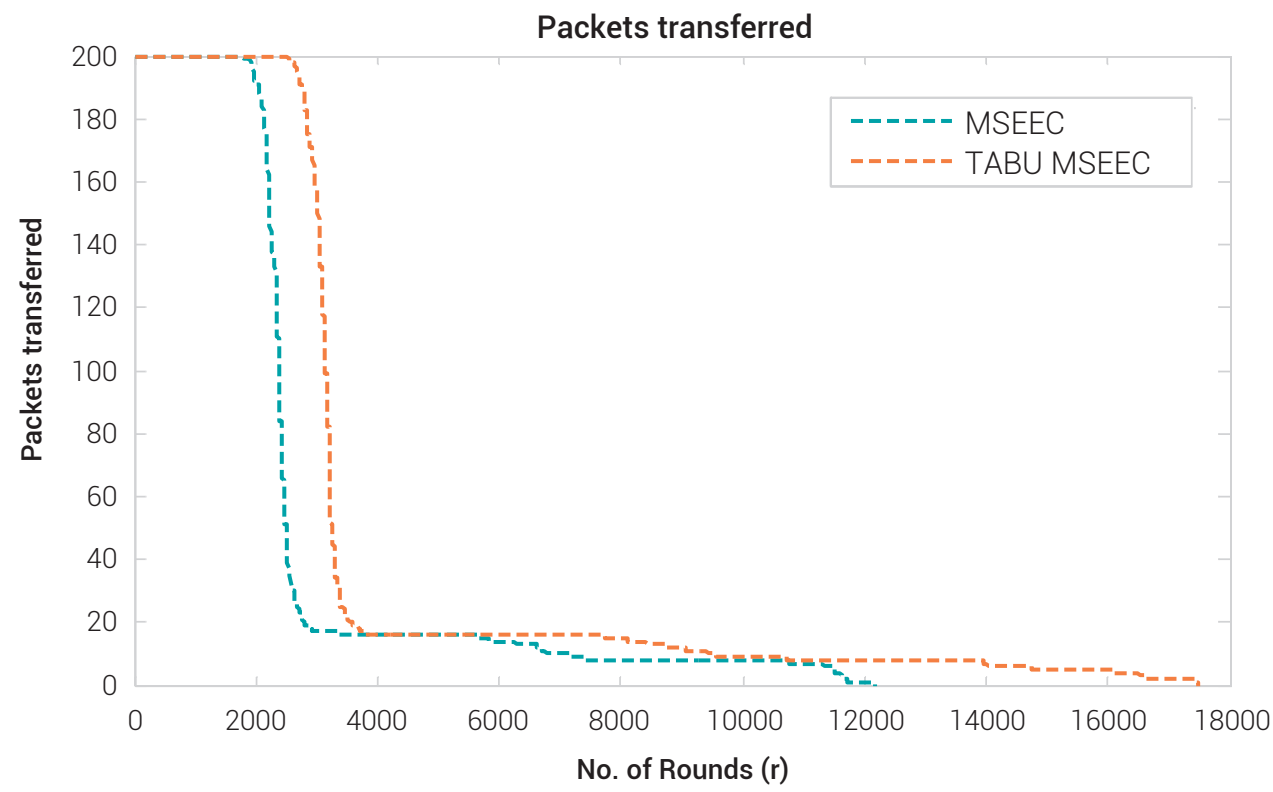

Figure 7. Packets transferred vs. rounds for 200 nodes in $200 \times 200$ network Source: own work 
Figure 7represents the throughput in the WSN, which means the total packets received at the BS. The network's lifespan is goodwhen the death rate of the nodes is less and vice-versa. When the alive nodes are high, it will send more data to theBS. It has been shown that TABU-MSEEC proved to be better than MSEEC. In MSEEC,the packets which aresent to the BS is at 12050 rounds while for TABU-MSEEC it is after 17000 rounds.

\section{Evaluation of MSEEC and TABU- MSEEC in terms of remaining average energy}

It is the amount of energy left with sensor nodes. It is computed in the beginning of each round during execution of the algorithm. This parameter helps to determine the stability period, consumption of energy and lifetime of WSNs. The residual energy is a major parameter to be considered for WSNs, that is calculated using

$$
\operatorname{RemEng}(\mathrm{re})=\sum_{\mathrm{N}=1}^{\mathrm{n}} \mathrm{E}_{\mathrm{rr}}(\mathrm{Nd})
$$

Where $\mathrm{E}_{\mathrm{rr}}(\mathrm{Nd})$ is the energy of $\mathrm{Nd}^{\text {th }}$ node for $\mathrm{n}^{\text {th }}$ round.

Here, it is seen from the results that the average energy consumed is around 2200 rounds in MSEEC, whereasforTABU-MSEEC, it occurs even after 3500 rounds in the case of NNs.In the case of ANs, the average energy consumed is after 7500 rounds in MSEEC, while it occurs in the case of TABU-MSEEC even after 11500 rounds. In the case of super nodes the average energy consumed is after 12000 rounds in MSEEC, while it occurs in the case of TABU-MSEEC even after 17000 rounds. Here, the observations reveal that the performance of TABUsearch is very high when compared to the MSEEC protocol because TABU search chooses the most effective solution. 


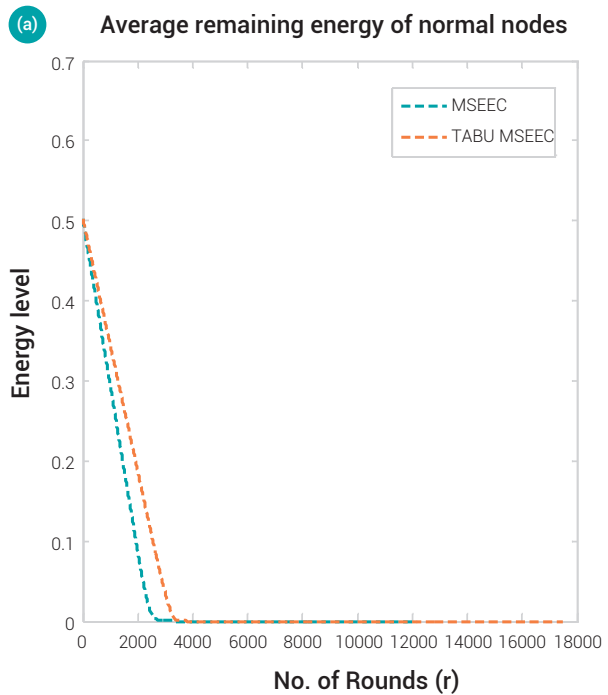

(b) Average remaining energy of advance nodes

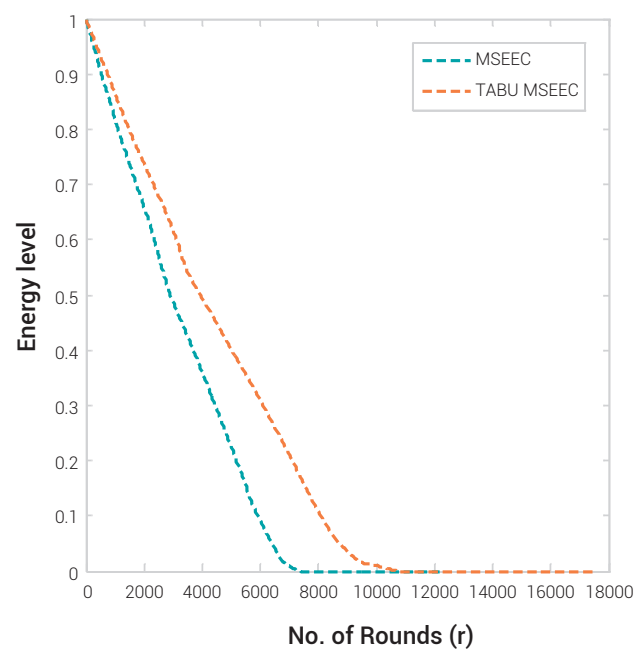

(c) Average remaining energy of super nodes

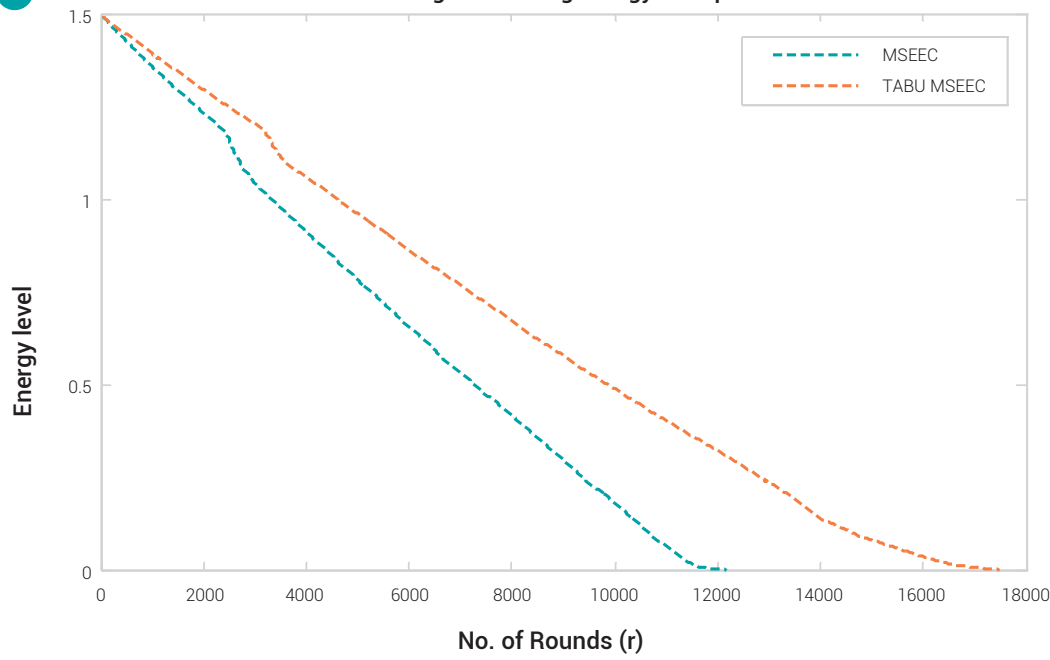

Figure 8. Average remaining energyvs. rounds for 200 nodes in a $200 \times 200$ network Source: own work
(a) Normal Nodes
(b) Advanced Nodes
(c) Super Nodes

\section{CONCLUSION AND FUTURE DIRECTIONS}

The TABU-MSEEC protocol presents an improvement over the MSEEC protocol. The method adopted for transmission is governed by the candidate solution of the TABU. If the proposed solution has greater effectivenessthanthe existing optimum solution, 
then it is updated into the TABU list and the solution is judged to be a TABU.If it is $T A B U$, then the $2^{\text {nd }}$ best solution is selectedfor the steps and if it is not TABU, then the solution is updated as the existing solution and the TABU list is updated. This approach may lead to a greater stability period and makes the network more efficient. The proposed techniqueis better than the existing one since the remaining energy in the network is increased by $62 \%$ compared to normal nodes in MSEEC, 65\% compared to advanced nodes in MSEEC and 70\% compared to super nodes in MSEEC. The network lifetime is also enhanced by $70.8 \%$ when compared to MSEEC. The simulated results shows the improvements of TABU-MSEEC over MSEEC. The FND is delayed by 1450, 1950 and 3500 rounds in NN, ANand SN respectively. Also, the LND is delayed by 100, 4200 and 5000 rounds in NN, AN and SN respectively. As a future work, the gathered data can be utilized to decide the impact of the path loss in applications that rely upon RSSI and the path loss exponent, for example, RSS-based confinement and energy analysis and also work on clustering and routing with other bio-inspired algorithms like cuckoo search, flower pollination, spider monkey optimization, Glow-worm and Meerkat Clan Algorithm.

\section{REFERENCES}

[1] I.F.Akyildiz, M. C.Vuran, “Wireless sensor networks", John Wiley \& Sons, The Atrium, Southern Gate, Chichester, West Sussex, PO198SQ, United Kingdom, vol. 4, pp. 1-491, 2010. [Online]. Available: https://books.google.co.in/books?hl=en\&lr=\&id=7YBHYJsSmS8C\&oi=fnd\&pg=PR7 \&ots=Q08Umf5hrf\&sig=mqpGrEcMh0q9WcbzaDSrALazPZQ\#v=onepage\&q\&f=false.

[2] Varsha, M.Bala, M Kumar, "An Energy-Efficient routing protocol based on TABU-Genetic Strategy in Wireless Sensor Network," International Journal of Advanced Networking and Applications, vol.10 (6), pp. 4099-4104, 2019. [Online]. Available: .

[3] S. Rani, R. Talwar, J. Malhotra, "A novel scheme for an energy efficient Internet of Things based on wireless sensor networks", Sensors, vol. 15 (11), pp. 28603-28626.[Online].doi: https://doi. org/10.3390/s151128603.

[4] N. Sharma, A.Nayyar, "A comprehensive review of cluster based energy efficient routing protocols for wireless sensor networks," International Journal of Application or Innovation in Engineering \& Management (IJAIEM), vol. 3(1), pp. 441-453, 2014. [Online].doi: https://pdfs. semanticscholar.org/4e1a/ 1da4c61bff31a2925fd86f2ebdd41e9189e9.pdf. 
[5] Varsha, M. Bala, M. Kumar, N.Kumar, "Development of QoS optimized routing using Artificial bee colony and TABU-GA with a mobile base station in Wireless Sensor Network," International Journal of Innovative Technology and Exploring Engineering (IJITEE), vol. 9 (1), pp. 926-933, 2019. [Online]. Available: https://www.ijitee.org/wp-content/uploads/papers/v9i1/K18390981119. pdf.

[6] Varsha, M. Bala, M. Kumar, N. Kumar, "Hybrid TABU-GA Search For Energy Efficient Routing In WSN,"International Journal of Recent Technology and Engineering (IJRTE),vol. 8(4), pp. 3250-3256, 2019. [Online]. Available: https://www.researchgate.net/profile/Neeraj_Kumar 238/ublication/337591277_Hybrid_TABUGA_Search_for_Energy_Efficient_Routing_in_ WSN/links/5ddf66ad299bf10bc32bb5a3/Hybrid-TABU-GA-Search-for-Energy-EfficientRouting-in-WSN.pdf.

[7] N. Kumar, A. Agrawal, R. A. Khan, "A Site Selection SchemeforEmergency Network Deployment: A metro city perspective,"Research journal of Engineerng and Technology, vol. 8, no.4, 2017, pp. 347-350. [Online].doi: 10.5958/2321-581X.2017.00060.5.

[8] Varsha, M. Bala, M. Kumar, "Randomization of Node Scheme with Optimization in Wireless Sensor Network," International Journal of Advanced Networking and Applications, vol. 10 (5), pp. 3999-4006, 2019. [Online].doi: 10.35444/ijana.2019.10053.

[9] K.Vijayalakshmi, P. Anandan, " A multi objective TABU particle swarm optimization for effective cluster head selection in WSN,” Cluster Computing,vol. 22 (5), pp. 12275-12282,2018. [Online].doi: https://doi.org/10.1007/s10586-017-1608-7.

[10] S. Kaur, R. Mahajan, "Hybrid meta-heuristic optimization based energy efficient protocol for wireless sensor networks," Egyptian Informatics Journal, vol. 19(3), pp. 145-150, 2018. [Online]. doi: https://doi.org/10.1016/j.eij.2018.01.002

[11] T. Shankar, S.Shanmugavel, A. Rajesh, "Hybrid HSA and PSO algorithm forenergy efficient cluster head selection in wireless sensor networks," Swarm and Evolutionary Computation, vol. 30, pp. 1-10, October 2016.[Online].doi: https://doi.org/10.1016/j.swevo.2016.03.003.

[12] A. Amuthan, K.D. Thilak, "Survey on TABU search meta-heuristic optimizationin 2016 International Conference on Signal Processing, Communication, Power and Embedded System (SCOPES)” pp. 1539-1543, IEEE, 2016. [Online]. doi:10.1109/SCOPES.2016.7955697.

[13] C. H. V .Raghavendran, G. N. Satish, , P. S. Varma, "Intelligent routing techniques for mobile ad hoc networks using swarm intelligence," IJ Intelligent Systems and Applications, vol. 1, pp. 81-89, 2013. [Online].doi: 10.5815/ijisa.2013.01.08. 
[14] F. Farouk, R. Rizk andF. W. Zaki,“Multi-level stable and energy-efficient clustering protocol in heterogeneous wireless sensor networks," IET Wireless Sensor Systems, vol. 4, no. 4, pp. 159-169, 2014. [Online].doi: 10.1049/iet-wss.2014.0051.

[15] R. Tandon, S. Nandi, "CRP: Cluster head Re-election Protocol for heterogeneous wireless sensor networks". In 2013 Fifth International Conference on Communication Systems and Networks (COMSNETS) , pp. 1-10. IEEE,2013. [Online]. Available: https://www.academia.edu/2085714/ CRP_Cluster_Head_Reelection_Protocol_for_heterogeneous_wireless_sensor_networks.

[16] S. Mahajan, J. Malhotra, S. Sharma, "An energy balanced QoS based cluster head selection strategy for WSN," Egyptian Informatics Journal,vol. 15(3), pp. 189-199, 2014. [Online].doi: https://doi.org/10.1016/j.eij.2014.09.001.

[17] S. J. Habib, P. N. Marimuthu, "Reputation analysis of sensors' trust within tabu search". In World Conference on Information Systems and Technologies, vol. 570, pp. 343-352, 2017. Springer, Cham.[Online].doi: https://doi.org/10.1007/978-3-319-56538-5_35.

[18] S. Y. Kuo, Y. H. Chou, "Entanglement-enhanced quantum-inspired tabu search algorithm for function optimization,"IEEE Access,vol. 5,pp.13236-13252, 2017.[Online].doi: https://doi. org/10.1109/ACCESS.2017.2723538

[19] K. Vijayalakshmi, P. Anandan, "A multi objective Tabu particle swarm optimization for effective cluster head selection in WSN," Cluster computing, vol. 22, no.5, pp. 12275-12282, 2019. [Online].doi: 10.1007/s10586-017-1608-7.

[20] F. Glover, “Tabu search: A tutorial,"INFORMS Journal on Applied Analytics/nterfaces, vol. 20, no. 4, pp. 1-185, 1990. [Online].doi: https://doi.org/10.1287/inte.20.4.74

[21] W. B. Heinzelman, A. P. Chandrakasan, and H. Balakrishnan, "An application-specific protocol architecture for wireless microsensor networks," IEEE Transactions on wireless communications, vol.1, no. 4, pp. 660-670, 2002. [Online]. Available: file://D:/Chrome\%20Downloads/ leach\%20(1).pdf. 